\title{
Article \\ DMSO Deintercalation in Kaolinite-DMSO Intercalate: Influence of Solution Polarity on Removal
}

\author{
Berenger ZOGO MFEGUE ${ }^{1}$, Jean Aimé MBEY ${ }^{2, * \mathbb{C}}$, Sandotin Lassina COULIBALY ${ }^{3}$, Vincent Laurent ONANA $^{1}$ \\ and Paul-Désiré NDJIGUI ${ }^{1}$
}

1 Department of Earth Sciences, University of Yaounde 1, P.O. Box 812 Yaounde, Cameroon; zogoberenger@yahoo.com (B.Z.M.); onana.vl@gmail.com (V.L.O.); Indjigui@yahoo.fr (P.-D.N.)

2 Department of Inorganic Chemistry, University of Yaounde 1, P.O. BOX 812 Yaounde, Cameroon

3 School of Mining and Energy, University of Man, P.O. Box 20 Man, Ivory Coast; coulibaly@univ-man.edu.ci or sando.coul@yahoo.fr

* Correspondence: mbey25@yahoo.fr

Citation: ZOGO MFEGUE, B.; MBEY, J.A.; COULIBALY, S.L.; ONANA, V.L.; NDJIGUI, P.-D. DMSO Deintercalation in Kaolinite-DMSO Intercalate: Influence of Solution Polarity on Removal. J. Compos. Sci. 2021, 5, 97. https://doi.org/10.3390/jcs5040097

Academic Editor:

Francesco Tornabene

Received: 16 March 2021

Accepted: 31 March 2021

Published: 2 April 2021

Publisher's Note: MDPI stays neutral with regard to jurisdictional claims in published maps and institutional affiliations.

Copyright: (c) 2021 by the authors. Licensee MDPI, Basel, Switzerland. This article is an open access article distributed under the terms and conditions of the Creative Commons Attribution (CC BY) license (https:// creativecommons.org/licenses/by/ $4.0 /)$.

\begin{abstract}
This study focused on the deintercalation of dimethyl sulfoxide (DMSO) from a kaoliniteDMSO complex in various solvents. The use of kaolinite as filler in polymer-clay composite generally faced the difficulty of kaolinite dispersion due to its high cohesion. For improved dispersion of kaolinite within a given matrix, previous intercalation of small polar molecules is usually done prior to its displacement during composite-making. The influence of the solvent polarity on the deintercalation in analyzed here to understand its role during the deintercalation process. The intercalation of the DMSO was done by solution-mixing and its displacement was done in distilled water, ethyl acetate, and acetone. The products of deintercalation were analyzed using Fourier transform infra-red (FTIR), powder X-ray diffraction (XRD), and differential scanning calorimetry (DSC). The weakening of the kaolinite cohesion after DMSO intercalation is demonstrated through the broadening of the diffraction peak associated with the kaolinite on XRD patterns. From FTIR spectra, the weakening is associated with the displacement to low wavenumbers of the $\mathrm{Si}-\mathrm{O}$ or $\mathrm{Al}-\mathrm{O}$ vibration bands within the kaolinite-DMSO complex. The kaolinite dehydroxylation temperatures from DSC show that the rate of DMSO displacement affects the ordering of the recovered kaolinite. The crystallite size of the kaolinite is reduced from the raw to the recovered kaolinite after DMSO displacement, indicating an exfoliation of the kaolinite. From these results, it is found that the removal of the DMSO from the kaolinite-DMSO complex is influenced by solvent polarity. The higher the polarity, the greater the removal of the DMSO from the complex. Solvent polarity affects the rate of DMSO displacement, which influences the ordering of the recovered kaolinite. It is suggested that solvent polarity can be used to control the removal rate of DMSO, which may be key to the dispersion of the kaolinite platelets.
\end{abstract}

Keywords: kaolinite; intercalation; exfoliation; polarity; DMSO

\section{Introduction}

Clays are industrial materials used in many domains, such as paints, inks, rubbers, ceramics, and building materials. When developing eco-friendly plastics, to deal with pollution problems associated with fossil-based plastics, the use of biopolymers has been explored by scientists worldwide. The sensitivity of biopolymers to fluid diffusion and their low mechanical responses requires the use of fillers during the reinforcing phase [1]. Clay materials are among the most explored candidates for such uses. The interest in clays is due to their strong anisotropy and specific surface that influence the filler-matrix interactions $[2,3]$. Among clays, swelling clays, such as montmorillonite, Laponite, or Hectorite, are widely explored, given that their exfoliation, which favors their dispersion within the polymer matrix, is more easily achieved [4-7]. Kaolinite, despite its great 
abundance and purity of deposits [8], remains more scarcely explored [3,9]. However, improving its use is cost-effective, given its abundance.

The asymmetric structure of the kaolinite layer, due to the overlay of tetrahedral and octahedral sheets within the layer, induces strong superimposed dipoles that, together with hydrogen bonds between the silica ring and the aluminum surface, give a strong cohesive energy to the mineral $[10,11]$. This cohesive energy makes the kaolinite layer almost non-expansive, and hence poorly dispersible. To improve its use as fillers in polymer-clay composites, the exfoliation of the kaolinite layer is a key factor [12]. Kaolinite intercalation with small polar molecules, such as dimethyl sulfoxide (DMSO), urea, or formamide, is well known in the literature [13-17]. The intercalated kaolinites are used as intermediates in composite-making $[6,9,14,15,18,19]$. The development of kaolinite-polymer composites is still challenging, as the dispersion of kaolinite to nano size is not easily achieved. The kaolinite-DMSO intermediate is used in many studies [3]. The preparation of the kaolinite-DMSO intermediate is done in various ways, including solution intercalation [12], homogenization intercalation (wet mixing) [20], or mechanochemical process [21]. As the intercalation within the kaolinite layer is also variable, Mbey et al. (2020) [22] recently explored the influence of kaolinite crystallinity on the intercalation of DMSO and established that increased crystallinity is favorable for DMSO intercalation.

The use of kaolinites in the reinforcing phase in polymer-clay (nano)composites are rare $[3-6,9,23,24]$. However, some recent works indicates that the use of kaolinite can be improved if convenient dispersion is achieved $[3,9,25]$. These studies used kaolinite-DMSO as an intermediate to improve the dispersion of clay within a polymer matrix. The study of kaolinite-DMSO complexes shows that the intercalated molecule influences H-bonding within the kaolinite layer, which results in a less cohesive structure [12]. In the present study, it is proposed that the intercalation-deintercalation process can be of interest to reduce the cohesion of the kaolinite crystallite. Given that the rate of deintercalation may affect the kaolinite structure, the removal of intercalated DMSO is carried out in three solvents including water, ethyl acetate, and acetone. The media were chosen because of their differences in polarity, as the driving out of DMSO is probably dependent on solvent polarity. X-ray diffraction (XRD), Fourier transform infra-red (FTIR), and thermal analysis were used to analyze the kaolinite-DMSO intercalate and the products of deintercalation.

\section{Materials and Methods}

\subsection{Materials}

An alluvial clay from the Lokoundjé subdivision was used. This was previously characterized in a study by Ndjigui et al., 2018 [26]. The sample was wet-sieved at $75 \mu \mathrm{m}$ to increase its kaolinite content. The collected cake was dried to constant weigh at ambient temperature for one week before being crushed and kept in polyethylene bags. The sieved sample was named GR375.

Analytical grade DMSO by Fluka was used for the preparation of kaolinite-DMSO intermediates.

For the deintercalation, three solvents of different polarity were selected. The selection was done according to the polarity of the intercalated molecule, here DMSO, whose relative polarity is 0.444 . The solvents' relative polarities as extracted from Reichardt and Welten 2011 [27] are given in Table 1.

Table 1. Relative polarity of the solvents used.

\begin{tabular}{ccc}
\hline Solvent & Polarity & Chemical Grade (Purity) \\
\hline Distilled water & 1 & \\
Acetone & 0.355 & Analytical (98\%) \\
Ethyl acetate & 0.228 & Analytical $(>98 \%)$ \\
\hline
\end{tabular}




\subsection{Methods}

For the DMSO intercalated complex, a mixture made of $200 \mathrm{~mL}$ of DMSO, $20 \mathrm{~mL}$ of distilled water, and $30 \mathrm{~g}$ of clay was placed in a glass jar. The resulting suspension was maintained at the ambient temperature of the laboratory $(28 \pm 1){ }^{\circ} \mathrm{C}$ for ten days. A manual shaking of $5 \mathrm{~min}$ was applied daily for each jar for ten days. The solid clay was recovered from the suspension by centrifugation at $2000 \mathrm{rpm}$ using a HERAUS MegaFuge 8 centrifuge by Thermo-Scientific. The collected cake was air-dried for five days before being dried at $100{ }^{\circ} \mathrm{C}$ in an oven to constant weight. The DMSO intercalated sample was codified GR375-D.

Displacement of DMSO from the kaolinite was performed using ethyl acetate, acetone, and distilled water. The products were respectively labeled GR375-AE, GR375-AC, and GR375-E.

For the GR375-AE preparation, $3 \mathrm{~g}$ of GR375-D was placed in $100 \mathrm{~mL}$ of ethyl acetate. The mixture was refluxed at $70{ }^{\circ} \mathrm{C}$ (boiling temperature of ethyl acetate) for one hour. The solid phase was collected after centrifugation at $2000 \mathrm{rpm}$ and dried in ambient temperature for $24 \mathrm{~h}$, then at $100{ }^{\circ} \mathrm{C}$, for $24 \mathrm{~h}$, in an oven. For the GR375-AC sample, acetone was used as a replacement for ethyl acetate and the same protocol was applied with the refluxing being done at $57^{\circ} \mathrm{C}$ (acetone boiling temperature). For GR375-E preparation, $3 \mathrm{~g}$ of GR375-D was dispersed in distilled water and reflux at $95^{\circ} \mathrm{C}$.

$\mathrm{X}$-ray diffraction of the various samples was performed at the Laboratory of Bioinorganic Chemistry and Catalyze at the University of Dusseldorf (Germany) using a Bruker D2 Phaser diffractometer operating with a $\mathrm{Cu}-\mathrm{K} \alpha$ radiation $(\lambda=1.54 \AA)$ and under a voltage of $30 \mathrm{kV}$. The XRD patterns were recorded at a speed of $0.01 \% \mathrm{~s}$ in a 2-theta range of $5^{\circ}$ to $70^{\circ}$.

For the differential scanning calorimetry (DSC), the equipment used was a coupled TGA-DSC Metller Toledo (3-SARe system) operating at a speed of $5{ }^{\circ} \mathrm{C} / \mathrm{min}$ from 25 to $1000{ }^{\circ} \mathrm{C}$ under a nitrogen atmosphere and a gas flow speed of $70 \mathrm{~mL} / \mathrm{min}$. The analysis was done at the Technische Universität Berlin (Germany)

The infra-red radiation analysis of the samples was carried out at the Laboratory of Applied Inorganic Chemistry at the University of Yaounde I using a BRUKER OPTIK ALPHA spectrometer. Each spectrum was acquired as an accumulation of 20 scans.

\section{Results}

\subsection{DMSO Intercalation: Structural Evolution by XRD, FTIR, and DSC}

$X$-ray diffraction patterns (Figure 1) show the total displacement of the characteristic $\mathrm{d}_{001}$ reflection peak of kaolinite from $7.14 \AA$ to $10.90 \AA$. The increase in the interlayer space is $3.76 \AA$ and it is consistent with a monolayer insertion of the DMSO [28].

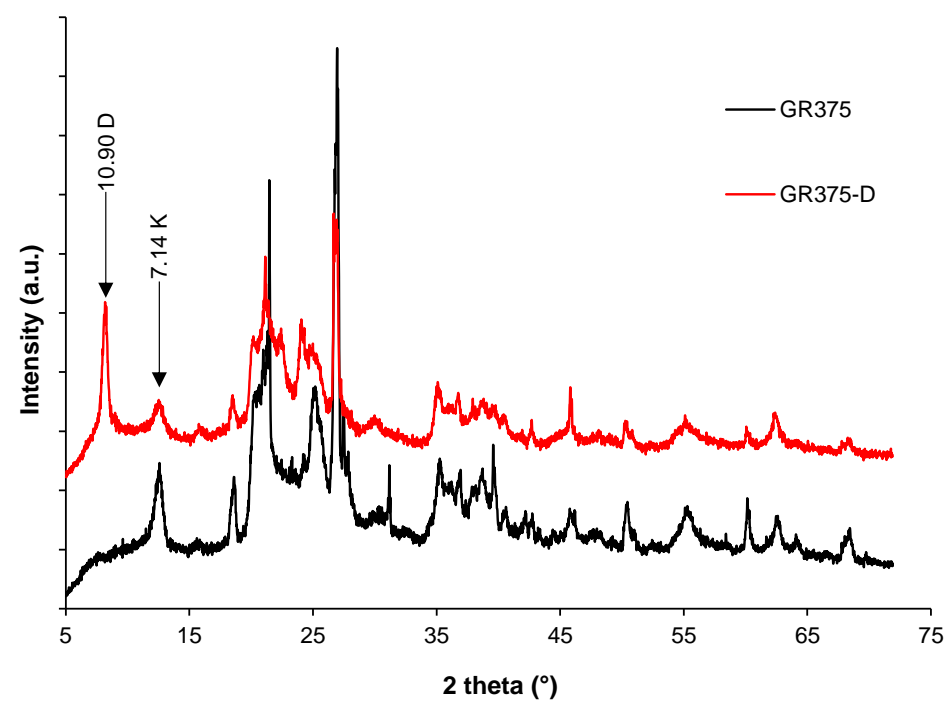

Figure 1. XRD pattern of raw (GR375) and DMSO intercalated (GR375-D) kaolinite. 
An intercalation ratio (I.R) value of $60.6 \%$ is calculated by Equation (1), assuming, for both expanded and unexpanded phase, the same degree of particle orientation $[12,29]$. The intercalation ratio is low and, as proposed by Mbey et al. 2020 [22], it is coherent with a poor crystallinity for the kaolinite sample.

$$
I . R=[I i(001) /(\operatorname{Ii}(001)+I k(001))] \times 100
$$

where $I_{i(001)}$ is the $\mathrm{d}_{001}$ peak intensity due to intercalation; $I_{k(001)}$ is the residual intensity of kaolinite basal peak in the intercalated product and I.R is the intercalation ratio.

On the FTIR spectra (Figure 2), the O-H stretching bands at $3655 \mathrm{~cm}^{-1}, 3696 \mathrm{~cm}^{-1}$ and $3621 \mathrm{~cm}^{-1}$ are attributed to kaolinite $\mathrm{O}-\mathrm{H}$ stretching $[12,30]$. The absence of the band usually observed around $3670 \mathrm{~cm}^{-1}$, is indicative of a poor crystallinity for the kaolinite [31]. After intercalation, the band around $3655 \mathrm{~cm}^{-1}$ in the raw sample his highly modified and appears at $3658 \mathrm{~cm}^{-1}$ (Figure 2b), due to the modification of its H-bonding interactions, which are now influenced by the sulfonyl group $(\mathrm{S}=\mathrm{O})$ from the DMSO. This modification of the $\mathrm{O}-\mathrm{H}$ stretching mode is evidence of the intercalation of DMSO within the kaolinite structure [12]. This is confirmed by the C-H stretching bands at $3001 \mathrm{~cm}^{-1}$ and $2950 \mathrm{~cm}^{-1}$ (Figure 2a). The deformation bands of those C-H bonds are observed at 1439, 1410, and $1320 \mathrm{~cm}^{-1}$ (Figure 2c). The asymmetric deformations band of free water molecules at $1652 \mathrm{~cm}^{-1}$ is increased in the kaolinite-DMSO complex, indicating a co-intercalation of water molecules which is confirmed by the $\mathrm{O}-\mathrm{H}$ stretching bands at 3545 and $3471 \mathrm{~cm}^{-1}$ (Figure 2a). In the fingerprint region (Figure 2c), deformation bands for $\mathrm{Si}-\mathrm{O}$ are registered at $999 \mathrm{~cm}^{-1}$, in the raw sample and are shifted to low wavenumber in the complex at $997 \mathrm{~cm}^{-1}$. Also, $\mathrm{Al}-\mathrm{O}$ at $909 \mathrm{~cm}^{-1}$ in the raw is shifted at $906 \mathrm{~cm}^{-1}$ in the intercalated form. The shifting is associated to the modification of the $\mathrm{H}$-bonding due to the sulfonyl group from the intercalated DMSO. Their shifting to low wavenumbers is coherent with low interaction energy in comparison to the interaction within the raw sample. These interaction modifications are evidence of the kaolinite internal cohesion weakening, as also established by Mbey et al., 2013 [12].

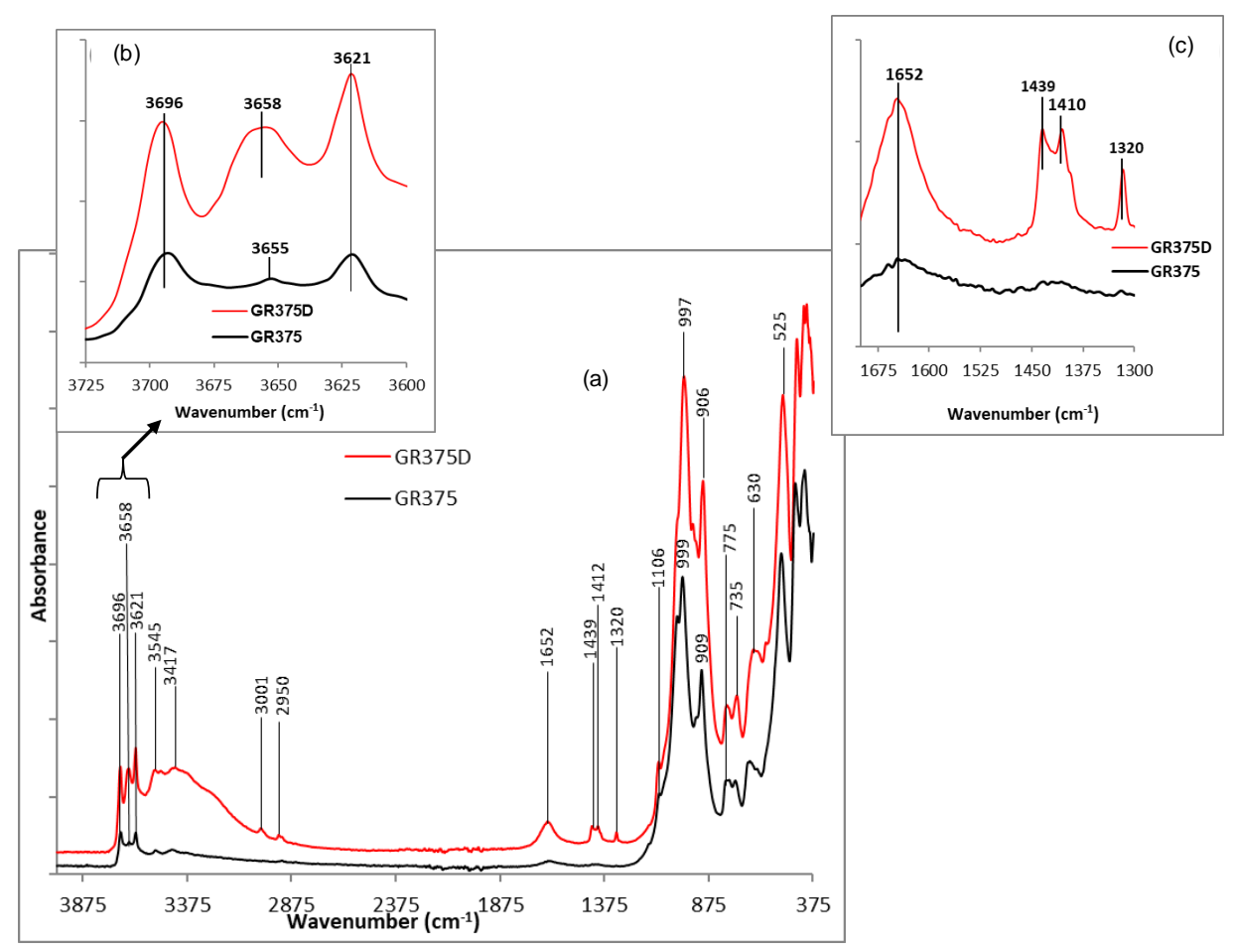

Figure 2. FTIR spectra of the raw sample (GR375) and the DMSO intercalated (GR375-D) (a) complete spectra (b) zoom of the $\mathrm{O}-\mathrm{H}$ stretching bands (c) zoom from $1675 \mathrm{~cm}^{-1}$ to $1300 \mathrm{~cm}^{-1}$. 
The DSC curves of the raw and intercalated kaolinite sample are presented in Figure 3. Three endothermic bands, centered around 70, 270, and $496{ }^{\circ} \mathrm{C}$, are observed for the raw sample (GR375). In the intercalated products (GR375D), five endothermic bands are registered at $80,129,193,270$, and $493{ }^{\circ} \mathrm{C}$. For both GR375 and GR375-D, the first endothermic bands $\left(70{ }^{\circ} \mathrm{C}\right.$ for the raw and $80{ }^{\circ} \mathrm{C}$ for the intercalated) are associated with the release of free water molecules in the samples (hydration water). The endothermic band at $270{ }^{\circ} \mathrm{C}$ is associated with the conversion of goethite into hematite. The peak at $129^{\circ} \mathrm{C}$ on the DSC of GR375-D is associated with the release of the co-intercalated water molecules, which are ordered due to their linkage through H-bonding with the DMSO and the clay internal surface. At $193^{\circ} \mathrm{C}$, the release of the intercalated DMSO is observed. Given that this temperature is close to DMSO boiling temperature $\left(189^{\circ} \mathrm{C}\right)$, it is concluded that DMSO has evaporated from the kaolinite-DMSO complex. Dehydroxylation of the kaolinite and its conversion into metakaolinite is observed at $496{ }^{\circ} \mathrm{C}$ in the raw and at $493{ }^{\circ} \mathrm{C}$ for kaolinite-DMSO complex (GR375-D). It is suggested that the intercalation of DMSO weakens the interlayer interactions, as the dehydroxylation is lower in the intercalated product. A similar result was reported using the controlled-rate thermal analysis by Mbey et al., 2013 [12].

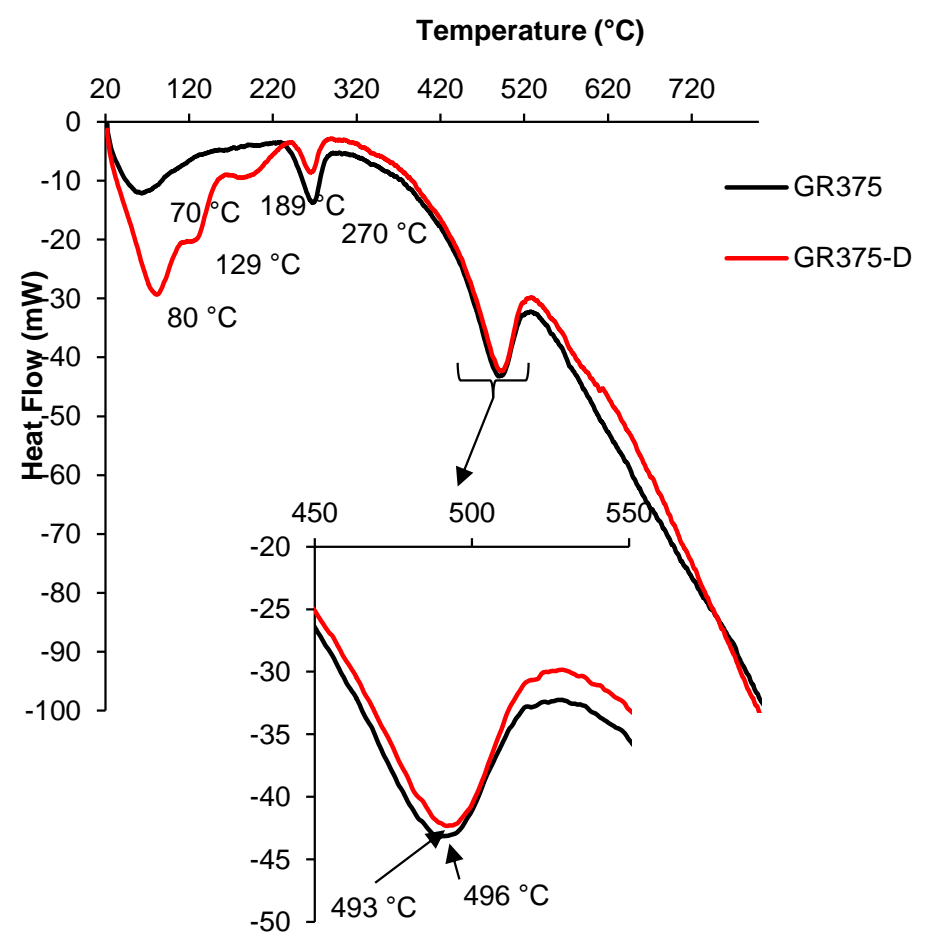

Figure 3. DSC analysis of the raw (GR375) and the DMSO intercalated (GR375-D) kaolinite.

\subsection{DMSO Deintercalation and Structural Evolution}

The kaolinite-DMSO complex was subjected to deintercalation in ethyl acetate (GR375$\mathrm{AE})$, Acetone (GR375-AC), and distilled water (GR375-E). The XRD patterns of the various products are presented in Figure 4. It is noted that in distilled water there is a complete removal of the intercalated DMSO as shown by the disappearance of the reflection peak at $10.90 \AA$, associated to the DMSO intercalation. The use of acetone and ethyl acetate leads to a low displacement of DMSO, as indicated by the characteristic peaks of the DMSO intercalation, which remain visible on their XRD patterns. Considering the relative intensity of the reflection associated with the DMSO intercalation, it is observed that ethyl acetate leads to lower removal of DMSO in comparison to acetone. In addition, the reflection peak of the recovered kaolinite after deintercalation of DMSO is broadened, and this was associated with a less ordered structure after deintercalation. The disordering is more marked for the product treated in acetone. 


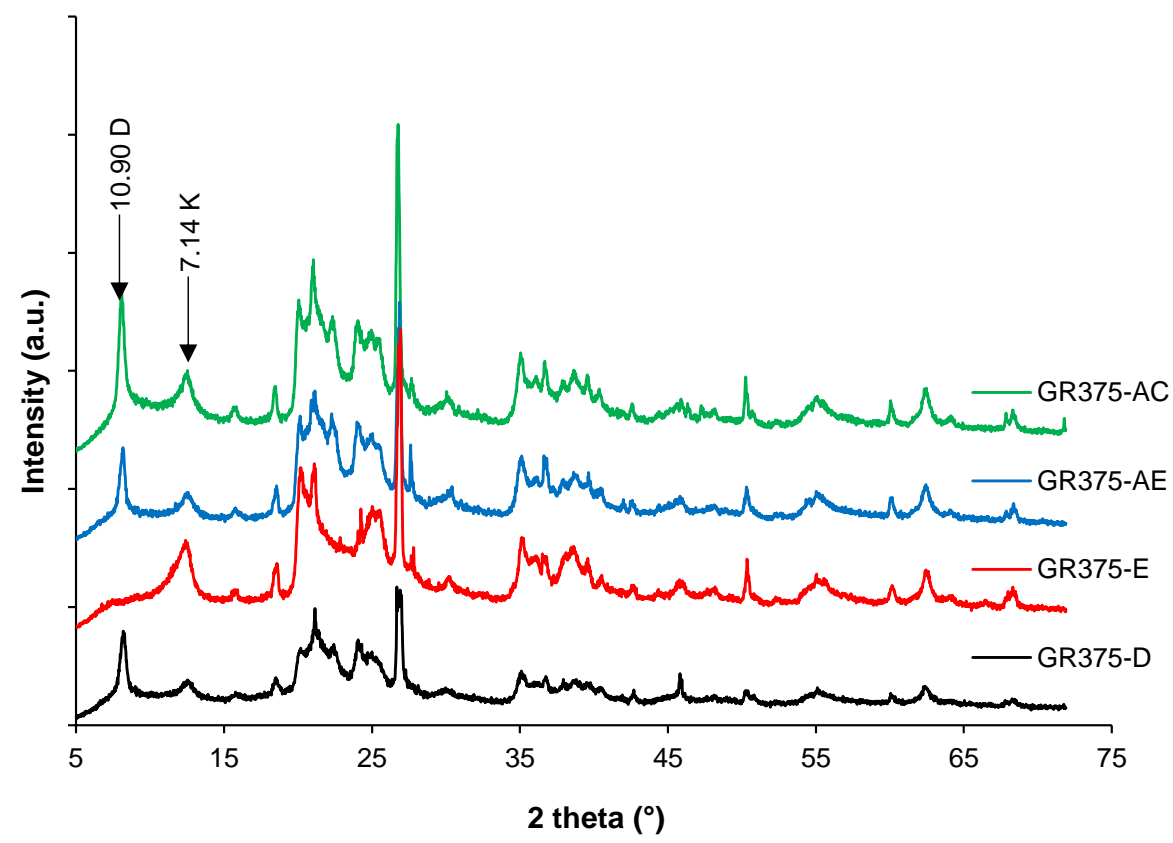

Figure 4. XRD patterns of the DMSO-Kaolinite (GR875-D) and the products of deintercalation in water (GR375E), in ethyl acetate (GR375-AE), and in acetone (GR375-AC). Note: $\mathrm{D}=$ kaolinite-DMSO complex; K: kaolinite.

The FTIR spectra are presented in Figure 5. From the global spectra (Figure 5a), the disappearance of characteristic C-H stretching bands at $3001 \mathrm{~cm}^{-1}$ and $2950 \mathrm{~cm}^{-1}$ and their deformation bands at 1439, 1410, and $1320 \mathrm{~cm}^{-1}$, on the GR375-E spectra, confirms the total removal of DMSO after treatment in water. An enlargement of the $\mathrm{O}-\mathrm{H}$ stretching region (Figure $5 b$ ) demonstrates the partial removal of products treated in ethyl acetate (GR875-AE) and acetone (GR875-AC). As proposed from XRD, the relative intensity of the vibration band at $3658 \mathrm{~cm}^{-1}$ is coherent with less removal by treatment in ethyl acetate. The product GR375-E, recovered after DMSO removal in distilled water, shows almost the same features as the raw kaolinite (see Figure 2b), indicating a total removal of DMSO.
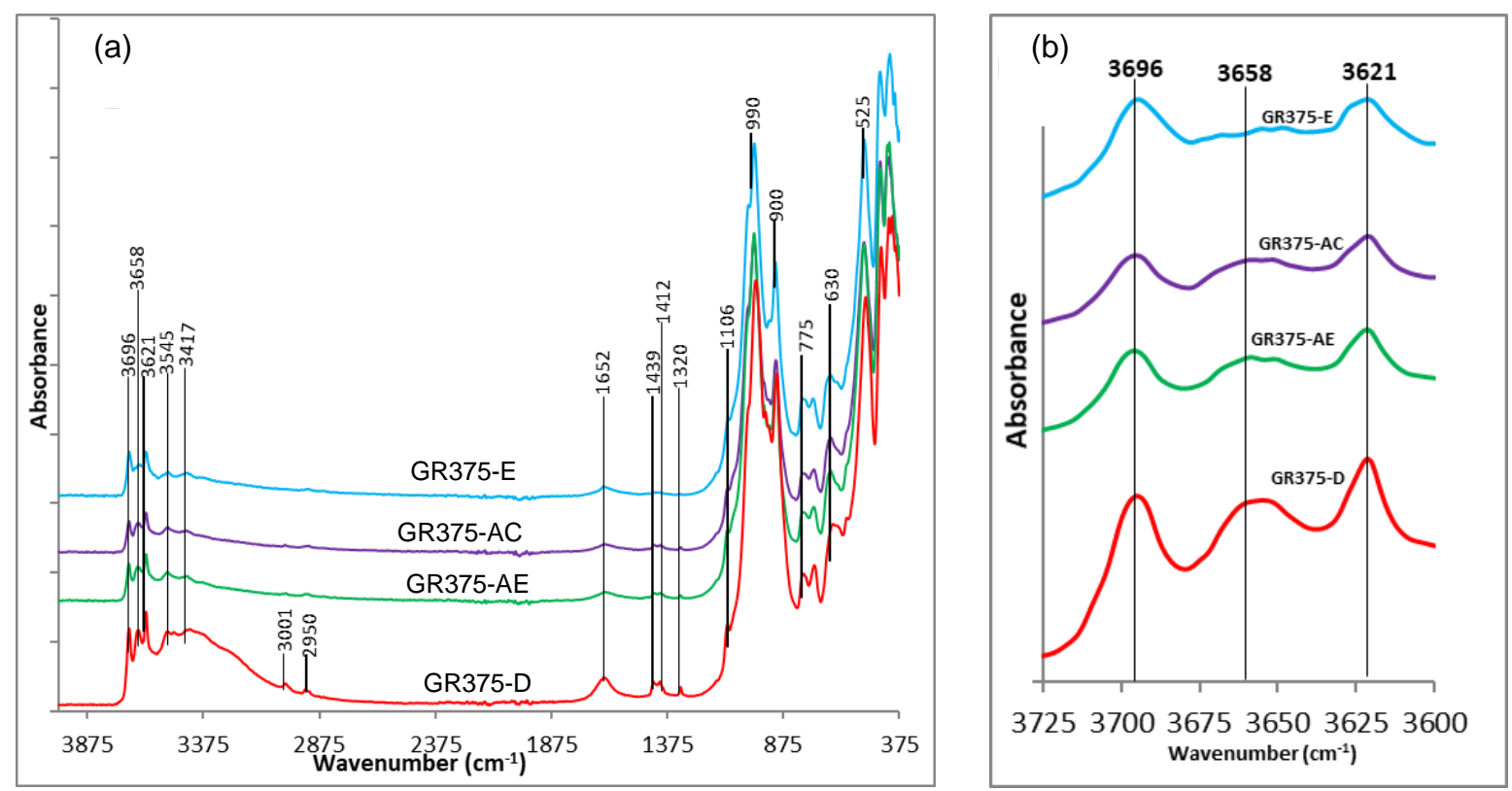

Figure 5. FTIR (a) complete spectra and (b) zooming of the $\mathrm{OH}$ stretching domain of DMSO-Kaolinite (GR875-D) and the products of deintercalation in water (GR375-E), in ethyl acetate (GR375-AE) and in acetone (GR375-AC). 
From both XRD (Figure 4) and FTIR (Figure 5) analyses, the DMSO removal range is as follows: water > acetone > ethyl acetate. It is concluded that, for the efficient removal of intercalated DMSO, solvent polarity should be higher than that of DMSO.

The DSC result of the kaolinite dehydroxylation in the products of deintercalation are plotted in Figure 6. The region of $450{ }^{\circ} \mathrm{C}$ to $550{ }^{\circ} \mathrm{C}$ is presented, given that it is within this range that dehydroxylation occurred. Below $450{ }^{\circ} \mathrm{C}$, thermal behavior is the same as previously depicted (see Figure 3, Section 3.1).

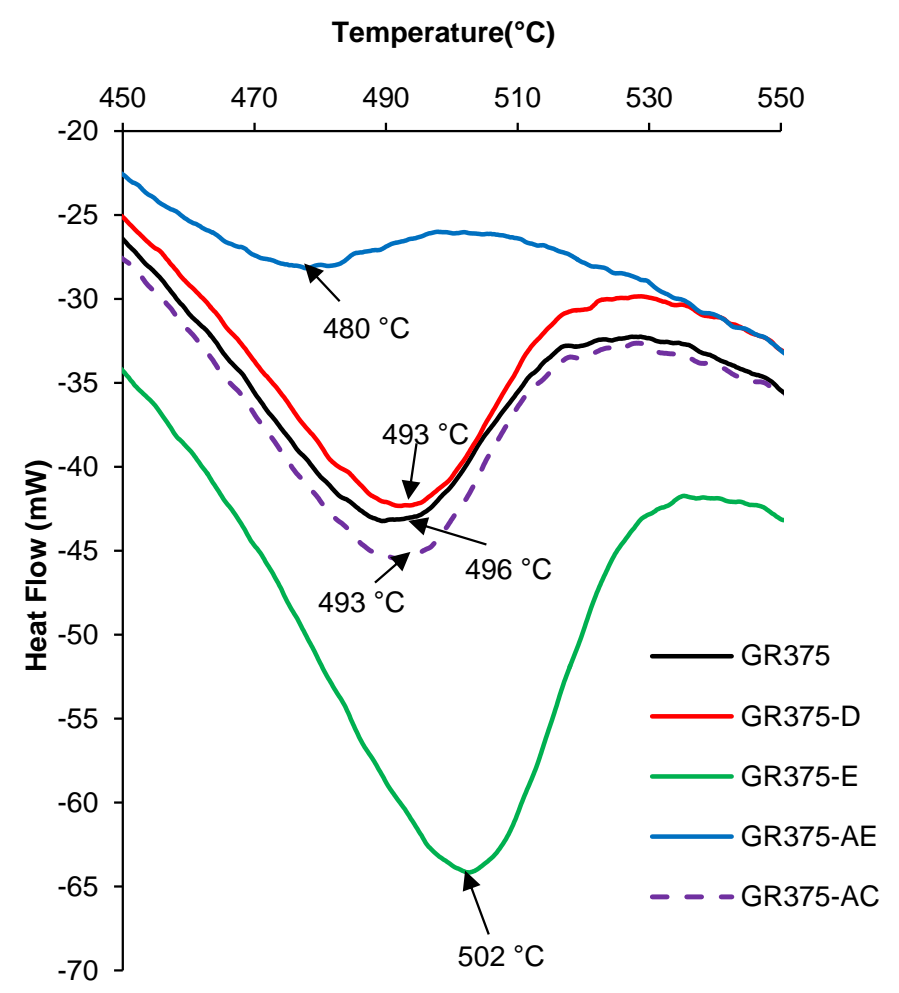

Figure 6. DSC dehydroxylation of the raw kaolinite (GR375); the kaolinite-DMSO (GR375-D) and the deintercalation products in water (GR375-E), in ethyl acetate (GR375-AE) and in acetone (GR375-AC).

The registered dehydroxylation temperatures are 480,493 , and $502{ }^{\circ} \mathrm{C}$, respectively for GR375-AE, GR375-AC, and GR375-E. When these temperatures are compared to that of the intermediate GR375-D, for which the dehydroxylation temperature is $493{ }^{\circ} \mathrm{C}$, it appears that the weakening of the kaolinite structure is preserved by the existence of the kaoliniteDMSO complex. Although partial removal occurs in acetone (GR375-AC) as well as in ethyl acetate (GR375-AE), the difference in the dehydroxylation temperature is far from negligible. It is suggested that the rate of the DMSO removal influences the organization of the kaolinite structure. The lowest dehydroxylation temperature $\left(480^{\circ} \mathrm{C}\right)$ registered for GR375-AE is proposed to be due to a rate of removal that affects the clay platelet orientation, leading to increased disordering. Conversely, rapid removal promotes an orderly return of clay sheets in their preferred orientation, which favors conservation of the initial structural organization. This justifies the highest dehydroxylation temperature $\left(502^{\circ} \mathrm{C}\right)$ registered for GR375-E, which was also associated with the departure of intercalated ions in the raw samples. In acetone, the slow rate of removal leads to minor evolution of the structure in both regions (DMSO-kaolinite and recovered kaolinite upon DMSO removal). That is why the dehydroxylation temperature $\left(493^{\circ} \mathrm{C}\right)$ obtained is comparable to both GR375 and GR375-D dehydroxylations, which were respectively registered at $496^{\circ} \mathrm{C}$ and $493{ }^{\circ} \mathrm{C}$. The polarity of the removal media influences the structure of the recovered kaolinite, as revealed by the variation of the dehydroxylation temperature.

The influence of the DMSO removal on the kaolinite structure evolution was accessed by calculating the crystallite size using the Scherrer equation. The thickness of the coherent 
scattering domain was calculated and assimilated to crystallite size. The reflection peak of the $\mathrm{d}_{001}$ of the kaolinite mineral is used for the calculation. In the DMSO-kaolinite (GR375D), the reflection at $10.9 \AA$, related to the displaced the kaolinite $\mathrm{d}_{001}$ upon intercalation, is used. The number of layers per crystallite is estimated by dividing the coherent domain size by the value of the d-spacing associated to the reflection peak used. The results are presented in Table 2.

Table 2. Crystallite apparent size and number of layers.

\begin{tabular}{ccc}
\hline Sample & Crystallite Size $L(\AA)$ & Number of Layer/Sheet \\
\hline GR375 & 80 & 11 \\
GR375 D & 130 & 12 \\
GR375 AC & 50 & 07 \\
GR375 AE & 48 & 07 \\
GR375 E & 45 & 06 \\
\hline
\end{tabular}

The number of sheets per layer of GR375 and GR375D is almost the same, indicating that the intercalation of DMSO does not affect the ordering within the kaolinite layer as previously reported [22]. After intercalation, the removal of the DMSO leads to recovered kaolinites with crystallite size less than that of the raw sample (GR375). This reduction of the crystallite size from the raw to the recovered kaolinite after displacement of the intercalated DMSO, indicates that kaolinite is exfoliated. All the solvents lead to almost the same size of crystallite, indicating that the displacement mechanism does not affect the exfoliation. It is suggested that the driving force involved is the same. The breakage of the existing H-bonding by the intercalated DMSO is the key to the exfoliation. When coupled to the DSC results, the dispersion of the exfoliated kaolinite will be influenced by the solvent polarity, which determines the rate of the DMSO removal from the kaoliniteDMSO complex.

\section{Conclusions}

This work examined the displacement of the intercalated DMSO from a kaoliniteDMSO complex using solvents of different polarity. In polymer-clay composites, the use of kaolinite as filler is limited because of its high cohesion. Most studies using kaolinite as filler proceed through an intermediate, which is a kaolinite intercalated with small polar molecules. The displacement of the intercalated molecule in a later step is then used for composite preparation. Therefore, the analysis of the solvent polarity on the deintercalation is of interest for understanding the mechanism favorable to kaolinite exfoliation, and for improving dispersion in a given matrix. The various products were analyzed using XRD, FTIR, and DSC. From the results obtained, it is shown that the intercalation of DMSO weakens the clay cohesion. The deintercalation is shown to be total in distilled water, whereas in acetone and ethyl acetate, partial removal of DMSO is observed. The crystallite size is small in kaolinites recovered after DMSO removal, indicating an exfoliation of the kaolinite layer after intercalation-deintercalation, and their values do not vary with the solvent used. It was concluded that the breakage of the existing H-bond by DMSO during intercalation is the driving force for the exfoliation. Solvent polarity affects the rate of the DMSO removal, and this affects the structure of the recovered kaolinite. The structure ordering induced by the deintercalation is influenced by the rate of DMSO removal, which is dependent on the solvent polarity. Highly polar solvents lead to rapid DMSO removal, which promotes an orderly return of the kaolinite sheet and preserved the structural organization. For solvents of low polarity in comparison to DMSO, disordering may be induced when the polarity is somehow comparable to that of DMSO. In general, solvents of polarity higher than that of DMSO may lead to complete removal of DMSO, whereas those with polarity lower than that of DMSO will lead to partial removal. A convenient choice of a solvent may be of help in achieving an increased disordering of the recovered kaolinite after deintercalation. An increased disordering of kaolinite is of interest for the 
improvement of kaolinite dispersion in a composite matrix in which kaolinite is used as a filler.

Author Contributions: Conceptualization J.A.M.; Methodology, J.A.M., B.Z.M. and S.L.C.; formal analysis, J.A.M., B.Z.M. and V.L.O.; Investigations, J.A.M. and B.Z.M.; Resources, J.A.M., P.-D.N., S.L.C. and V.L.O.; Supervision, P.-D.N. and V.L.O.; Visualization, J.A.M. and B.Z.M.; Writing original draft-preparation, B.Z.M.; Writing-review and editing, J.A.M., S.L.C. and P.-D.N. All authors have read and agreed to the published version of the manuscript.

Funding: This research received no external funding.

Institutional Review Board Statement: Not applicable.

Informed Consent Statement: Not applicable.

Acknowledgments: The authors are grateful to the Cameroon government for the special research allowance to state universities staff. Matemb Ma Ntep Tobie is acknowledged for the XRD patterns acquisition. Djobo Yankwa Joël is acknowledged for the DSC data acquisition.

Conflicts of Interest: The authors declare no conflict of interest.

\section{References}

1. Sadasivuni, K.K.; Saha, P.; Adhikari, J.; Deshmukh, K.; Ahmed, M.B.; Cabubuhan, J.-J. Recent advances in mechanical properties of biopolymer composites: A review. Polym. Compos. 2020, 4, 32-59. [CrossRef]

2. Luo, J.-J.; Daniel, I.M. Characterization and modeling of mechanical behavior of polymer/clay nanocomposites. Compos. Sci. Technol. 2003, 63, 1607-1616. [CrossRef]

3. Mbey, J.A.; Hoppe, S.; Thomas, F. Cassava starch-kaolinite composite films. Thermal and mechanical properties related to filler-matrix interactions. Polym. Compos. 2015, 36, 184-191. [CrossRef]

4. De Carvalho, A.J.F.; Curvelo, A.A.S.; Agnelli, J.A.M. A first insight on composites of thermoplastic starch and kaolin. Carbohydr. Polym. 2001, 45, 189-194. [CrossRef]

5. Wilhelm, H.M.; Sierakowski, M.R.; Souza, G.P.; Wypych, F. The influence of layered compounds on the properties of starch/layered compounds composites. Polym. Inter. 2003, 52, 1035-1044. [CrossRef]

6. Chen, B.; Evans, J.R.G. Thermoplastic starch-clay nanocomposites and their characteristics. Carbohydr. Polym. 2005, 61, 455-463. [CrossRef]

7. Dintcheva, N.T.; Al-Malaika, S. Photo-stabilization of biopolymers-based nanocomposites with UV-modified layered silicates. Polym. Degrad. Stab. 2020, 179, 109252. [CrossRef]

8. Murray, H.H. Kaolin minerals: Their genesis and occurrences. In Hydrous Phyllosilicates; Bailey, S.W., Ed.; Mineralogical Society of America: Madison, WI, USA, 1988; Volume 19, pp. 67-89.

9. Mbey, J.A.; Hoppe, S.; Thomas, F. Cassava starch-kaolinite composite film. Effect of clay content and clay modification on film properties. Carbohydr. Polym. 2012, 88, 213-222. [CrossRef]

10. Giese, R.F. Kaolin Minerals: Structures and Stabilities. In Hydrous Phyllosilicates; Bailey, S.W., Ed.; Mineralogical Society of America: Chantilly, VA, USA, 1988; pp. 29-66.

11. Cabedo, L.; Giménez, E.; Lagaron, J.M.; Gavara, R.; Saura, J.J. Development of EVOH kaolinite nanocomposites. Polymers 2004, 45, 5233-5238. [CrossRef]

12. Mbey, J.A.; Thomas, F.; Ngally Sabouang, C.J.; Liboum Njopwouo, D. An insight on the weakening of the interlayer bonds in a Cameroonian kaolinite through DMSO intercalation. Appl. Clay Sci. 2013, 83-84, 327-335. [CrossRef]

13. Olejnik, V.S.; Posner, A.M.; Quirk, J.P. The intercalation of polar organic compound into kaolinite. Clay Miner. 1970, 8, 421-434. [CrossRef]

14. Tunney, J.J.; Detellier, C. Interlamellar covalent grafting of organic units on kaolinite. Chem. Mater. 1993, 5, 141-148. [CrossRef]

15. Costanzo, P.M.; Giese, R.E. Ordered halloysite: Dimethylsulfoxide intercalate. Clays Clay. Miner. 1986, 34, 105-107. [CrossRef]

16. Frost, R.L.; Kristóf, J.; Paroz, G.N.; Kloprogge, J.T. Intercalation of kaolinite with acetamide. Phys. Chem. Miner. 1999, 26, 257-263. [CrossRef]

17. Frost, R.L.; Makó, E.; Kristóf, J.; Horváth, E.; Cseh, T. The effect of mechanochemical activation upon the intercalation of a high-defect kaolinite with formamide. J. Colloid Interface Sci. 2003, 265, 386-395. [CrossRef]

18. Yanfeng, L.; Sun, D.; Pan, X.; Zhang, B. Kaolinite intercalation precursors. Clays Clay Miner. 2009, 57, 779-786.

19. Zhang, S.; Liu, Q.; Yang, Y.; Wang, D.; He, J.; Sun, L. Preparation, morphology, and structure of kaolinites with various aspect ratios. Appl. Clay Sci. 2017, 147, 117-122. [CrossRef]

20. Makó, E.; Kovács, A.; Kristóf, T. Influencing parameters of direct homogenization intercalation of kaolinite with urea, dimethyl sulfoxide, formamide, and N-methylformamide. Appl. Clay Sci. 2019, 182, 105287. [CrossRef]

21. Makó, E.; Kristóf, J.; Horváth, E.; Vágvölgyi, V. Mechanochemical intercalation of low reactivity kaolinite. Appl. Clay Sci. 2013, 83-84, 24-31. [CrossRef] 
22. Mbey, J.A.; Siewe, J.M.; Ngally Sabouang, C.J.; Razafitianamaharavo, A.; Kong, S.; Thomas, F. DMSO Intercalation in Selected Kaolinites: Influence of the Crystallinity. ChemEngineering 2020, 4, 66. [CrossRef]

23. Kaewtatip, K.; Tanrattanakul, V. Structure and properties of pregelatinized cassava starch/kaolin composites. Mater. Des. 2012, 37, 423-428. [CrossRef]

24. Zhang, Y.; Liu, Q.; Zhang, S.; Zhang, Y.; Zhang, Y.; Liang, P. Characterization of kaolinite/styrene butadiene rubber composite: Mechanical properties and thermal stability. Appl. Clay Sci. 2016, 124-125, 167-174. [CrossRef]

25. Mbey, J.A.; Thomas, F.; Hoppe, S. Kaolinite dispersion in cassava starch based composite films. A photonic microscopy and x-ray tomography study. J. Polym. Eng. 2018, 38, 641-647. [CrossRef]

26. Ndjigui, P.-D.; Onana, V.L.; Sababa, E.; Bayiga, E.C. Mineralogy and geochemistry of the Lokoundje alluvial clays from the Kribi deposits, Cameroonian Atlantic coast: Implications for their origin and depositional environment. J. Afr. Earth Sci. 2018, 143, 102-117. [CrossRef]

27. Reichardt, C.; Welten, T. Solvents and Solvent Effects in Organic Chemistry, 4th ed.; WILEY-VCH Verlag GmbH \& Co. KGaA: Weinheim, Germany, 2011; 718p, ISBN 978-3-527-32473-6.

28. Fang, Q.; Huang, S.; Wang, W. Intercalation of dimethylsulfoxide in kaolinite: Molecular dynamics simulation study. Chem. Physic. Lett. 2005, 411, 233-237. [CrossRef]

29. Wang, B.X.; Zhao, X.P. The influence of intercalation rate and degree of substitution on the electrorheological activity of a novel ternary intercalated nanocomposite. J. Solid State Chem. 2006, 179, 949-954. [CrossRef]

30. Ledoux, R.L.; White, J.L. Infrared studies of hydrogen bonding interaction between kaolinite surfaces and intercalated potassium acetate, hydrazine, formamide, and urea. J. Colloid Interface Sci. 1966, 21, 127-152. [CrossRef]

31. Cases, J.M.; Lietard, O.; Yvon, J.; Delon, J.F. Etude des propriétés cristallochimiques, morphologiques, superficielles de kaolinites désordonnées. Bull. Minéral. 1982, 105, 439-455. [CrossRef] 